\title{
EPR studies on the interaction between additives and polyethylene matrix initiated by gamma radiation
}

\author{
G. Przybytniak*, J. Sadlo, M. Walo \\ Institute of Nuclear Chemistry and Technology, Warsaw, Poland
}

Received 19 August 2019; accepted in revised form 7 October 2019

\begin{abstract}
Silane cross-linked polyethylene (PE) modified with two antioxidants (Irganox 1076 and Irganox PS802) and aluminum hydroxide (ATH) as a flame retardant, was irradiated with gamma rays at $77 \mathrm{~K}$. The radical processes initiated by radiation were investigated by Electron Paramagnetic Resonance (EPR) spectroscopy from $100 \mathrm{~K}$ to the temperatures at which the spectra disappeared. Interpretation of the experimental signals was proposed. The mechanism of the two-stage action of phenolic antioxidant on PE was suggested on the basis of EPR spectra of individual components. It was found that paramagnetic defects generated by radiation in ATH decayed in parallel and independently of radical processes in PE matrix due to phase separation. Thus, in contrast to antioxidants, they did not affect the degradation of the PE matrix. The decrease in concentration of ATH defects in the range of 100-190 K was more efficient in the dispersed phase of the polymer composite than in the microcrystalline ATH powder.
\end{abstract}

Keywords: damage mechanism, wires and cables, radical processes, polyethylene, antioxidant

\section{Introduction}

Various types of polyethylene have been widely used in the cable industry as insulating materials in the last decades [1-5]. They found applications in many Nuclear Power Plants (NPP), particularly as crosslinked compositions filled with selected additives that provide advantageous properties, such as thermal stability, reduced flammability, good processability and improved electrical properties, etc. [6-8]. Aging of polymer compositions occurs via different mechanisms affecting their functionality and lifetime. Despite the relatively simple elemental composition, polyethylene is a quite complex polymer due to various structural and morphological forms [9-12]. The presence of antioxidants or other additives significantly influence radiation/thermally induced oxidative degradation $[13,14]$. Additionally, they can modify crystallization during processing playing a role of nucleation agents. Thus, the properties for the same grade of polymer depend on both processing parameters and additives. Polyethylenes are stabilized against thermo-oxidative degradation or radiation induced degradation throughout their service lifetime under harsh conditions by primary stabilizers (antioxidants) and secondary stabilizers (hydroperoxide decomposers) able to scavenge radicals affecting the aging processes $[14,15]$.

The importance of antioxidants reactions is not fully recognized despite the fact that they can influence yield of radicals and the kinetics of their decay. Their impact can be followed only by direct observation of intermediates and analysis of radical processes.

It is well known that radicals are responsible for the deterioration of physicochemical and thermal properties during radiation induced aging. The process can be considerably suppressed by antioxidants present

$\overline{{ }^{*} \text { Corresponding author, e-mail: g.przybytniak@ichtj.waw.pl }}$ (C) BME-PT 
in plastics at a concentration of $0.5-1 \%[16,17]$. The nature of antioxidants is usually insightfully selected in order to efficiently protect the polymer.

In our studies, to monitor radicals in the irradiated compositions based on polyethylene (PE) matrix and the mechanisms of the reactions between products initiated by radiation, Electron Paramagnetic Resonance (EPR) spectroscopy was used under cryogenic conditions. A series of PE materials doped with phenolic and thioether antioxidants, together or separately, and additionally filled with flame retardant, were studied in order to determine influence of individual components on radical processes in polymeric matrix. All components and related contents were especially selected for this study. Two antioxidants were chosen for testing: primary antioxidant Irganox 1076 and secondary antioxidant Irganox PS802. Aluminium hydroxide (ATH) was used as a flame retardant.

The research is relevant for modelling the processes responsible for aging of polyethylene insulation in cables installed in the NPP $[1,2,18]$, especially in relation to their qualification and lifetime prediction $[3,4]$. The proposed approach might complement our knowledge about degradation mechanisms because in practice information on the composition/ formulation of polymeric materials is not disclosed by cable manufacturers.

\section{Materials and methods}

\subsection{Tested components and composites}

Studied materials were prepared in accordance with prior arrangements regarding components and contents. A silane (vinyltrimethoxysilane) cross-linked linear low density polyethylene (PE) with melting point at $121{ }^{\circ} \mathrm{C}$ and a density at $0.918 \mathrm{~g} / \mathrm{cm}^{3}$, commonly used to produce insulation, was applied as a matrix. Silane-grafted PE was produced on a twinscrew continuous mixer. The degree of crystallinity of PE determined by differential scanning calorimetry method was $33 \%$, assuming that the heat of fusion for $100 \%$ crystalline polymer is $293 \mathrm{~J} / \mathrm{g}$ [19].

PE was modified by selected additives often applied in insulating materials, namely: primary phenolic antioxidant (Irganox 1076), secondary thioether antioxidant (Irganox PS802) and flame retardant (ATH, $\mathrm{Al}(\mathrm{OH})_{3}$, with a particle diameter $d_{50}=1-2.2 \mu \mathrm{m}$ and a Specific Surface Area BET at 3-5 $\mathrm{m}^{2} / \mathrm{g}$ ). The composition of samples prepared in the form of $0.3 \mathrm{~mm}$
Table 1. The composition of the tested samples.

\begin{tabular}{|l|l|}
\hline \multicolumn{1}{|c|}{ Material } & \multicolumn{1}{|c|}{ Symbol } \\
\hline Silane cross-linked LLDPE & PE \\
\hline $\begin{array}{l}\text { Silane cross-linked LLDPE } \\
+1 \text { phr phenolic antioxidant }\end{array}$ & PE+I1076 \\
\hline $\begin{array}{l}\text { Silane cross-linked LLDPE } \\
+1 \text { phr thioether antioxidant }\end{array}$ & PE $+\mathrm{I} 802$ \\
\hline $\begin{array}{l}\text { Silane cross-linked LLDPE } \\
+1 \text { phr phenolic antioxidant } \\
+1 \text { phr thioether antioxidant }\end{array}$ & PE $+\mathrm{I} 1076+\mathrm{I} 802$ \\
\hline $\begin{array}{l}\text { Silane cross-linked LLDPE } \\
+50 \text { phr ATH }\end{array}$ & PE + ATH \\
\hline $\begin{array}{l}\text { Silane cross-linked LLDPE } \\
+50 \text { phr ATH } \\
+1 \text { phr phenolic antioxidant } \\
+1 \text { phr thioether antioxidant }\end{array}$ & PE $+\mathrm{I} 1076+\mathrm{I} 802+\mathrm{ATH}$ \\
\hline
\end{tabular}

thick tapes is listed in Table 1. The antioxidants and flame retardant were successively added to silane cross-linked polyethylene at the given concentrations.

\subsection{Irradiation and methodology of research}

Quartz tubes filled with the samples were tightly closed and irradiated in a gamma cell (Gamma Chamber 5000, BRIT) to a dose of $10 \mathrm{kGy}$ at a dose rate of $4.3 \mathrm{kGy} / \mathrm{h}$ in liquid nitrogen. Alanine dosimetry was performed according to ISO/ASTM 51607:2013(E) to determine precisely absorbed dose.

EPR measurements were carried out using an X-band EMXplus Bruker EPR spectrometer. The apparatus was equipped with a cryostat (temperature control system ER 4131VT) and a cylindrical resonant cavity with high sensitivity. The following parameters were applied: sweep width to $60.0 \mathrm{mT}$, microwave power $1 \mathrm{~mW}$, modulation amplitude $0.1 \mathrm{mT}$, time constant $10 \mathrm{~ms}$. Number of scans was adjusted to the intensity of the experimental signals. The spectra were measured at every $30 \mathrm{~K}$, from $100 \mathrm{~K}$ to the temperature at which the complete decay of radicals took place, using a controlled temperature annealing procedure. After heating, the samples were kept at the selected temperature for $5 \mathrm{~min}$ to achieve a thermal equilibrium. The spectra were analyzed using WinEpr software provided by Bruker. The radical concentration was determined by double integration of the experimental spectra. It was assumed that the amount of radicals at $100 \mathrm{~K}$ was $100 \%$. The decrease in the concentration of PE alkyl radicals was estimated taking into account intensity of the second high-field line. 


\section{Results and discussion}

\subsection{EPR spectroscopy of components}

Polyethylene

Several types of free radicals were found in irradiated polyethylene, in accordance with the previous studies [20-23]. The most abundant intermediate, secondary alkyl radical $\left(R_{\mathrm{PE}} 1\right)-\mathrm{CH}_{2}-{ }^{\bullet} \mathrm{CH}-\mathrm{CH}_{2}-$, was formed as a result of carbon-hydrogen bond scission. The radical was observed from 100 to $280 \mathrm{~K}$ (Figure 1a). It is a short-lived intermediate which completely decays at ambient temperature. The EPR spectrum of the radical showed sextet of hyperfine splitting $(h f s)$ about $3.0 \mathrm{mT}$. Due to conformational restrictions, anisotropy of $\alpha$ protons and broadening of line width, the peak resolution was poor.

The second radical demonstrating the septet of hfs $1.4 \mathrm{mT}$ with further complex splittings, probably in the form of doublet, was assigned to allyl type radical $-\mathrm{CH}_{2} \mathrm{C}^{\bullet} \mathrm{H}-\mathrm{CH}=\mathrm{CH}-\mathrm{CH}_{2}-,\left(\mathrm{R}_{\mathrm{PE}} 2\right)$. They are formed as a result of migration of unpaired electrons along the polymer chains until they encounter

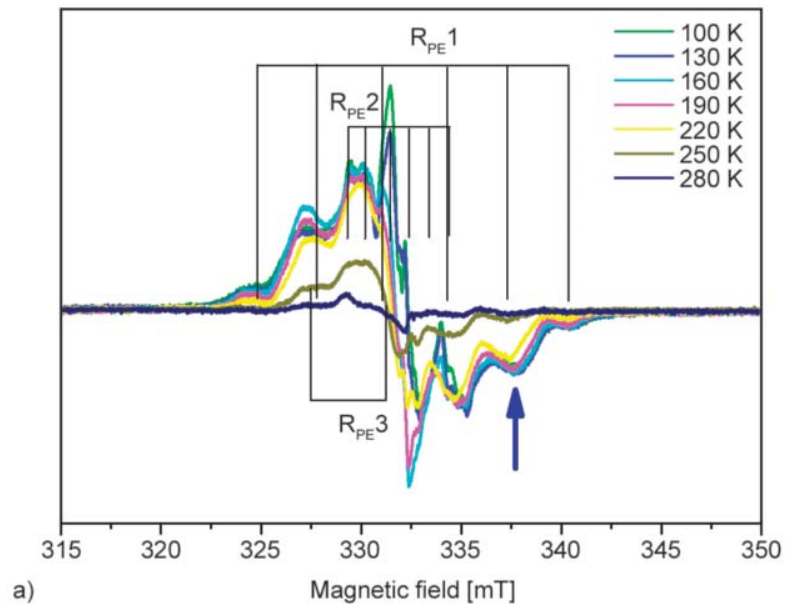

a)

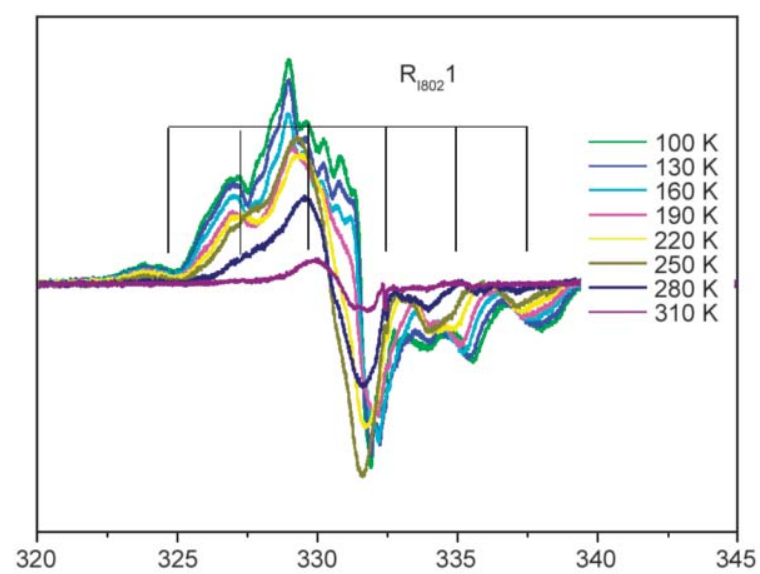

c)

$$
\text { Magnetic field [mT] }
$$

trans-vinylene groups, where spins become trapped due to a well-known resonance phenomena [22], or through direct hydrogen abstraction. In addition to alkyl and allylic radicals, a polyenyl-type product, $-\mathrm{CH}_{2} \mathrm{C} \cdot \mathrm{H}-(-\mathrm{CH}=\mathrm{CH}-)_{\mathrm{n}}-\mathrm{CH}_{2}-$ is present, showing a broad symmetric singlet.

As seen from Figure 1a, there were also radicals having a center at oxygen containing groups produced by oxidation of carbon radicals [24-26]. Polyethylene was stored in an air atmosphere, and was therefore saturated with oxygen. Due to oxygen access, carbon centered radicals converted to a peroxy radical $\left(\mathrm{R}_{\mathrm{PE}} 3\right)-\mathrm{CH}_{2}-\mathrm{CH}(\mathrm{OO} \bullet)-\mathrm{CH}_{2}-$. The process is efficient only in the amorphous phase, while in ordered domains oxidation is inhibited due to very limited diffusion of oxygen molecules in crystals. Thus, observed at higher temperatures alkyl radicals which avoided oxidation, were mainly located in the crystalline phase [27]. Peroxy radicals $\left(\mathrm{R}_{\mathrm{PE}} 3\right)$ of $g$-factors 2.031 and 2.0095 are able to abstract hydrogen from methylene groups of the main chain forming
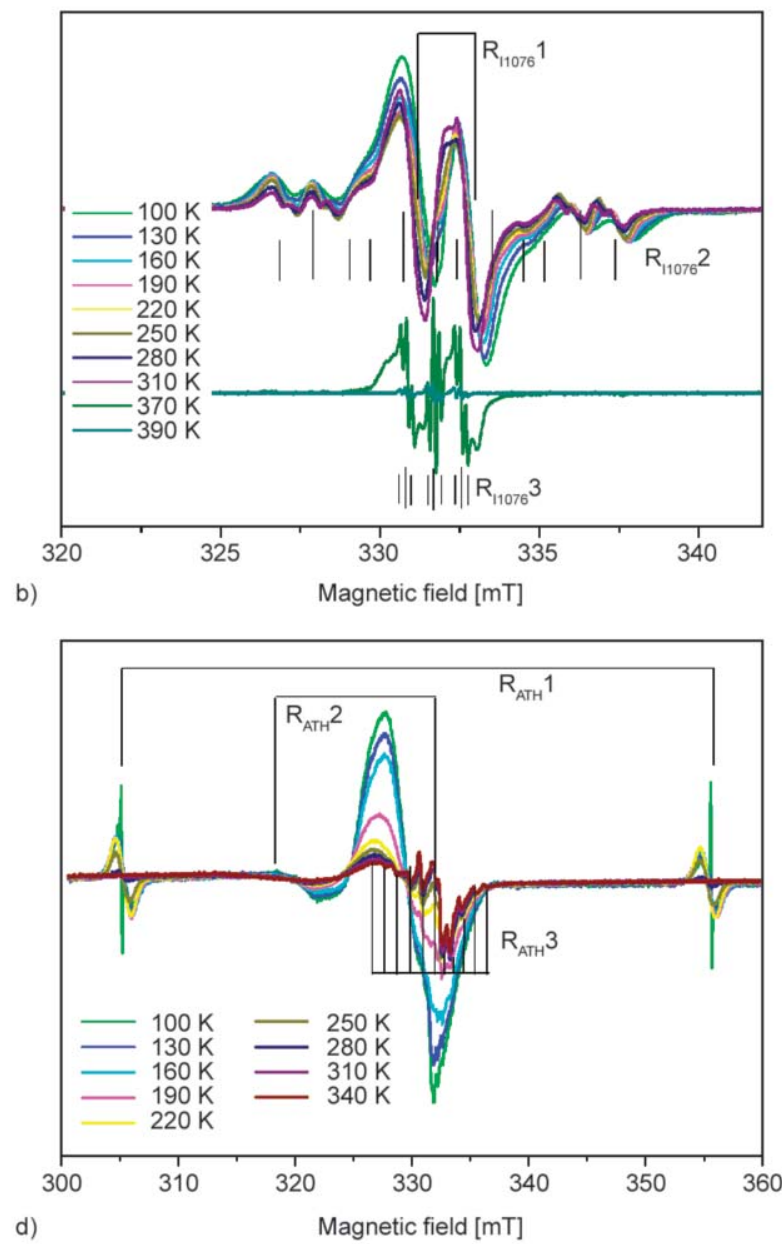

Figure 1. Sequences of EPR spectra of the samples gamma irradiated to a dose of $10 \mathrm{kGy}$ at $77 \mathrm{~K}$, after annealing to the indicated temperatures. a) PE; b) I1076; c) I802; d) ATH. 
hydroperoxides that are converted to carbonyl or carboxylic group and initiate chain oxidative degradation. Hydroperoxide decomposition seems to be particularly important in LLDPE having significant number of short branches and therefore many labile tertiary hydrogen atoms [28].

\section{Irganox 1076}

Sterically hindered phenolic antioxidants attract attention due to versatile applications in food industry, biology and industrial applications. They are primary antioxidants used in polymer processing to protect the materials during manufacture and aging. Their architecture is tailored to the chemical structure of plastics and to the secondary antioxidants to achieve a synergistic effect. After adding to polymeric materials, they form suspension due to aliphatic hydrocarbon residues, which increase compatibility between components. Irganox 1076 showing a linear response to low doses, was in the past considered as a dosimeter for clinical applications, appropriate for various types of ionizing radiation. There were reports in the literature, that in the polymeric matrix it can form after irradiation one, stable radical observed by EPR spectroscopy [29-31].

However, as seen in Figure 1b, the signals of microcrystalline Irganox 1076 powder are more complex. The spectrum of antioxidant irradiated with gammarays at $77 \mathrm{~K}$ and recorded at $100 \mathrm{~K}$ consists of at least two components. The intensive doublet of $h f_{s}$ $1.71 \mathrm{mT}$ was assigned to the phenolic radical cation (Figure 2, $\mathrm{R}_{11076} 1$ ) formed after electron loss by the hydroxyl group. The intermediate shows a $g$-factor (2.0035) characteristic for this group of radicals [32]. The susceptibility of hydroxyl groups to deprotonation depends on the substituents of the aromatic ring and grows with their electron-withdrawing ability. Alkyl groups are considered substituents with moderate electron donor properties, weaker than alkoxyl
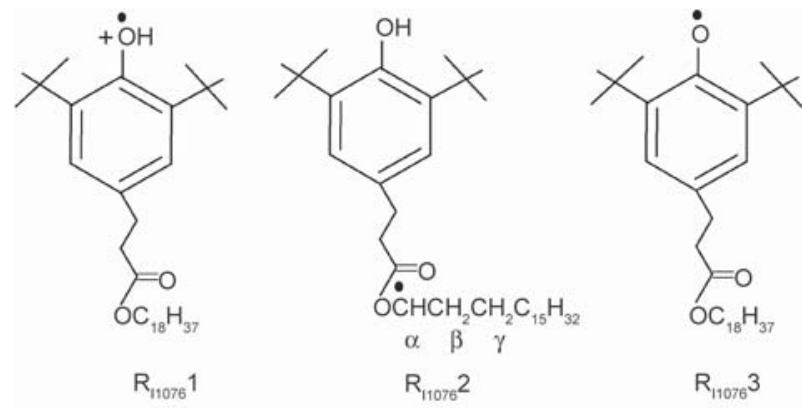

Figure 2. Structures of radicals generated in Irganox 1076 by gamma-rays. or amino groups. Due to the rigidity of the crystals, deprotonation in the powdered antioxidant is initially inhibited. The presence of a proton in the hydroxyl group significantly changes the distribution of spin density, decreasing the coupling with other substituents. The peak-to-peak (Hpp) intensity of alkyl radical $\mathrm{R}_{\mathrm{I} 1076} 1$ signal, measured as a distance between the minimum and maximum of the whole spectrum, decreased during heating.

At low temperatures we observed additional lines appearing on both sides of the dominant signal. They are components of the spectrum whose internal lines create a superposition with an intensive doublet. The whole spectrum seems to consist of a quartet of triplets of hyperfine splitting 2.71 and $1.21 \mathrm{mT}$, respectively. The stick diagram of the signal is marked $\mathrm{R}_{11076} 2$ in Figure $1 \mathrm{~b}$. Such a pattern can be attributed to the radical shown in the Figure 2. The unpaired spin interacts with three equivalent hydrogens, one $\alpha$ and two $\beta$ protons of the methylene group adjacent to the oxygen atom of the ester group situated in the para substituent. Hfs of two $\gamma$ hydrogens is greater than that of typical aliphatic radicals due to the influence of the ester group.

Above $340 \mathrm{~K}$ the spectrum changed significantly. A distinctive triplet of triplets appeared, which was attributed to phenoxy radical $\left(\mathrm{R}_{\mathrm{I1076}} 3\right)$ showing coupling of spin with hydrogen atoms of the methylene group in the para position $(1.20 \mathrm{mT})$ and two meta protons $(0.15 \mathrm{mT})$. As can be seen from the evolution of the EPR spectra, the only possible precursor of the intermediate is the radical showing the doublet at lower temperatures [33]. The conversion proves that the two intensive lines were correctly assigned to the phenolic radical cation. Above the melting point (323-328 K), due to the increasing conformational movements of macromolecules, the intermediate was deprotonated. Such a pattern was also found in solutions of other phenolic species, in which the loss of a proton was facilitated by a hydrogen bonding network $[34,36]$.

\section{Irganox 802}

Irganox 802 is a dialkyl ester of thiodipropionic acid. It is used as a heat stabilizer in combination with primary phenolic antioxidants. It provides long-term heat stabilization to polymeric materials and shows low volatility.

In Irganox 802, radiation generates alkyl radicals exhibiting a spectrum marked $\mathrm{R}_{\mathrm{I} 802} 1$ in Figure 1c. The 
signal was attributed to alkyl radicals whose centers interacted with five hydrogen atoms and were located at hydrocarbon domains. Above $220 \mathrm{~K}$, they were fast converted to peroxy radicals. In the central part of the experimental spectra there are unknown signals which could not be interpreted because of poor line resolution. Absorption is probably related to the radical centers localized in the vicinity of sulfur atom.

\section{ATH}

Aluminium hydroxide (ATH), which emits water above $220^{\circ} \mathrm{C}$, is used in a wide variety of compounds as a flame retardant [e.g. 36-38]. Gammarays modify ATH generating paramagnetic defects in the crystal lattice and hydrogen atoms demonstrating characteristic two lines at a distance of about $5,05 \mathrm{mT}\left(\mathrm{R}_{\mathrm{ATH}} 1\right)$ (Figure 1d). The doublet disappeared below $250 \mathrm{~K}$. Moreover, at low temperatures, a broad singlet appeared, which was presumably a superposition of various signals containing unresolved lines. The anisotropic singlet $\left(\mathrm{R}_{\mathrm{ATH}} 2\right)$ showing $g_{1}=$ 2.034 and $g_{2}=2.0002$ is usually assigned to $\mathrm{O}^{-}$paramagnetic ionic center trapped in the crystal [39]. The resulting $g$-factor, $g=2.0060$, is far from the value characteristic for free electron revealing the influence of oxygen centered radicals.

At elevated temperatures, eleven lines demonstrating hfs around $1.12 \mathrm{mT}$ were found $\left(\mathrm{R}_{\mathrm{ATH}} 3\right)$, which were assigned to radical anion $\mathrm{O}^{-}$interacting with two $\mathrm{Al}^{3+}$ centers. In the past, analogous structure $\mathrm{Al}-\mathrm{O}^{-}-\mathrm{Al}$ was found in irradiated $\mathrm{Al}_{2} \mathrm{O}_{3}$ [39].

The following sequence of reactions initiated by ionizing radiation is proposed:

$\mathrm{OH}^{-} \rightarrow \cdot \mathrm{OH}+\mathrm{e}^{-}$

$\bullet \mathrm{OH}+\mathrm{OH}^{-} \rightarrow \mathrm{H}_{2} \mathrm{O}+\mathrm{O}^{-}$

$\mathrm{OH}^{-} \rightarrow \mathrm{O}^{-}+\mathrm{H}$

\subsection{Polyethylene doped with antioxidants}

The series of EPR spectra were recorded for polyethylene containing antioxidants (Figure 3).

At low temperatures EPR spectra of virgin PE and PE doped with antioxidants are the same. There are no signals related to the presence of antioxidants in the range of 100-160 K. Such an effect was anticipated because their concentration was very low ( $1 \mathrm{phr})$ thus, the dominant target of ionizing radiation was the polymeric matrix.

The shape of EPR spectra recorded for polyethylene protected by antioxidants are different than in the case of virgin polyethylene from $190 \mathrm{~K}$, i.e. above
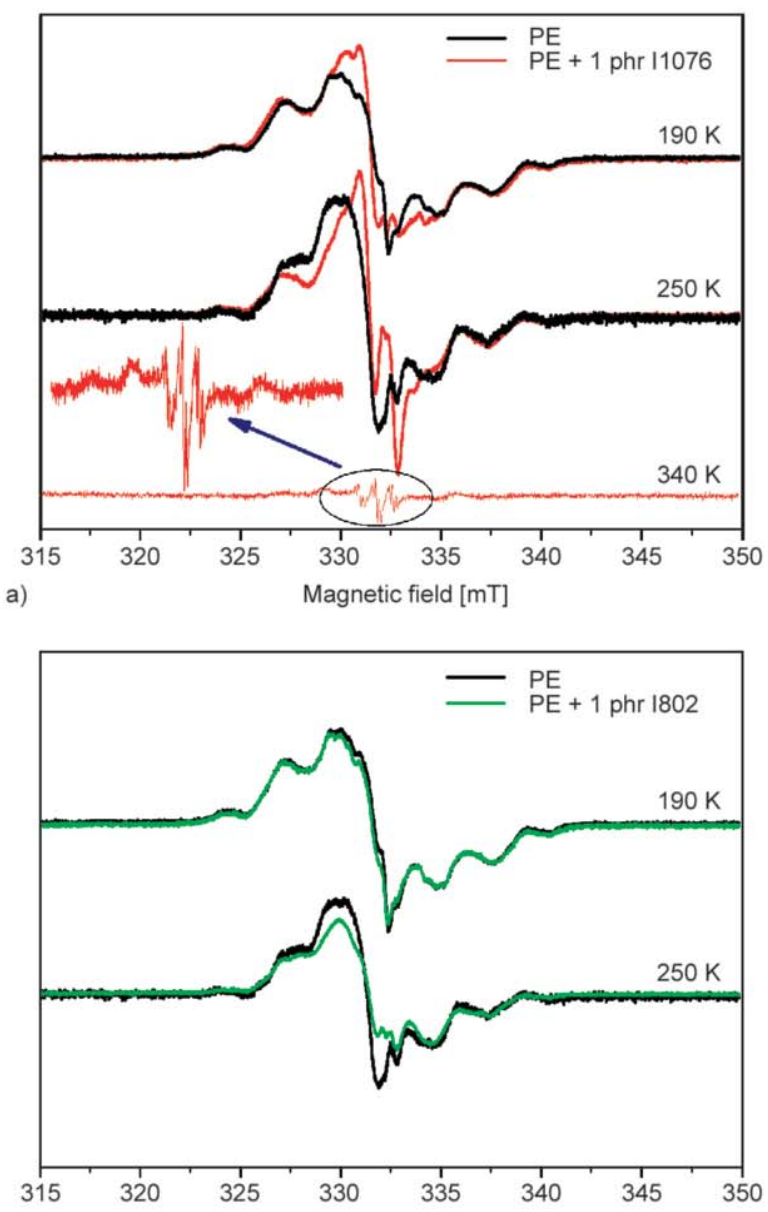

b) Magnetic field [mT]

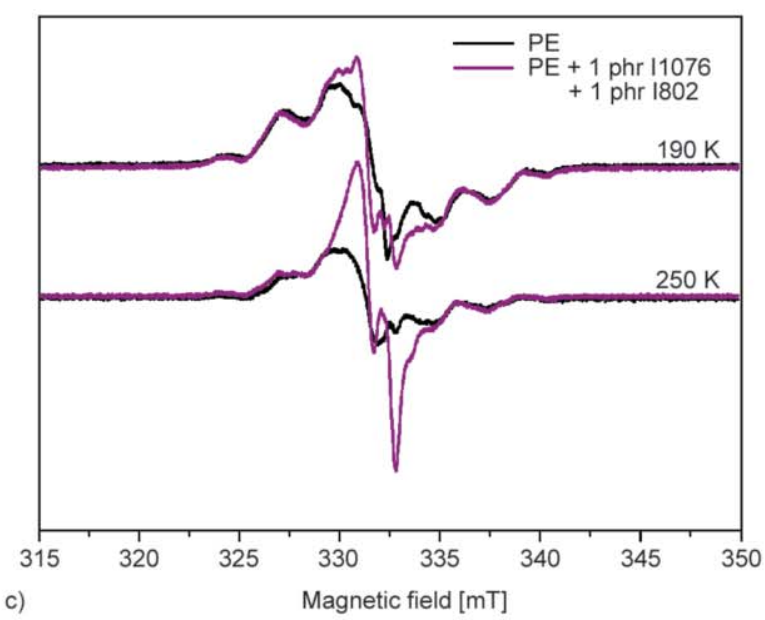

Figure 3. Sequences of EPR spectra of the materials gamma irradiated to a dose of $10 \mathrm{kGy}$ at $77 \mathrm{~K}$, upon annealing to the indicated temperatures. a) PE doped with 1 phr of I1076; b) PE doped with 1 phr of I802; c) PE doped with $1 \mathrm{phr}$ of I1076 and $1 \mathrm{phr}$ of $\mathrm{I} 802$.

glass transition temperature [40]. Thus, the additive has an impact on radiation induced processes in the polymer only when the movement of macromolecules in amorphous phases is sufficiently intensive. 
Antioxidants in PE are not homogeneously distributed throughout the material. They are located in the amorphous phase and interface regions because, during crystallization and crystal growth, additives are expelled from the ordered domains. Thus, concentration of antioxidants in the amorphous phase is higher than in lamellae regions. This phenomenon results in significant consequences: antioxidants are active mainly beyond crystalline phase. Therefore, antioxidants hardly influence radicals in the ordered areas. They have to slowly migrate towards the phase boundary where can be scavenged by antioxidants. On the other hand, above the glass transition temperature the mobility of the transients produced in the amorphous phase is relatively high which facilitates reaction with antioxidants. As seen in Figure 3, at $250 \mathrm{~K}$ the process significantly affected the profile of EPR spectra, particularly for samples comprising I1076. Interestingly, under these conditions a doublet appeared, i.e. a signal similar to that one attributed to phenolic radical cation (Figure 1b). Its hfs is about $0.2 \mathrm{mT}$ smaller than that determined for microcrystalline I1076. It should be taken into account that one of the doublet lines is superimposed on the absorption of peroxy radical interfering the exact determination of splitting. It is also possible that the bond between oxygen and hydrogen is slightly longer because of the vicinity of the macromolecule, which eventually acts as a hydrogen acceptor. This effect may weaken the interaction between unpaired spin and proton. The origin of the doublet was confirmed by the fact that it occurred only in the spectra of samples containing I1076. The shape of spectrum suggests

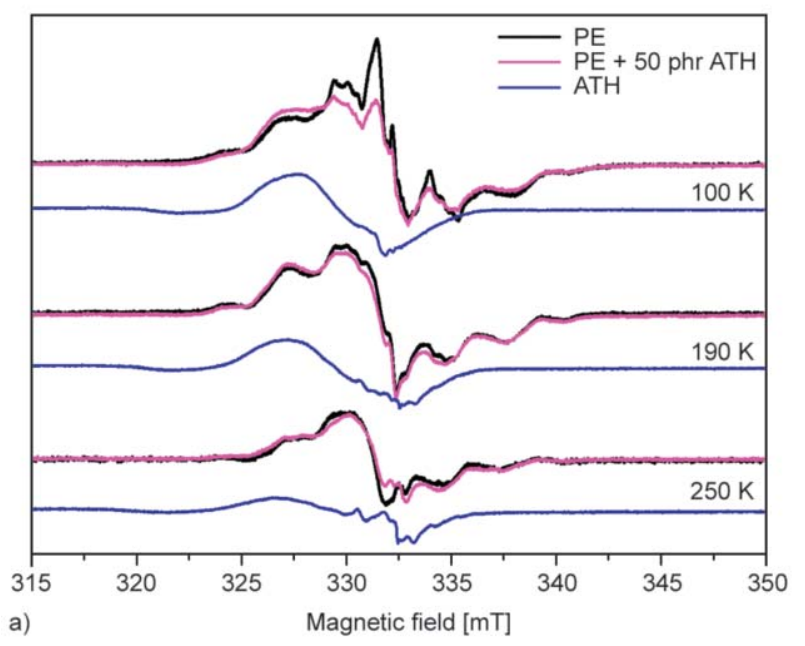

that at the first stage of the interaction between the macroradical and phenolic antioxidant the transfer of hydrogen atom from hydroxyl group is inhibited and only radical center changes localization. In the transient state the hydrogen atom is shared and just at higher temperatures the irreversible shift to $\mathrm{PE}$ is possible. Traces of the characteristic spectrum of phenoxy radical appeared at $340 \mathrm{~K}$.

Determination of $\mathrm{R}_{\mathrm{PE}} 1$ decay (on the basis of the intensity of the second high-field line, marked in Figure 1a with an arrow) revealed that the profile did not change distinctly in the presence of antioxidants as shown in the section 3.3. (at least within the limits of measurement error). Therefore, it seems that peroxy radical is the dominant reactant and hydrogen acceptor.

I802 affected insignificantly PE radicals, as seen in Figure $3 \mathrm{~b}$. The shape of signals remained almost unchanged except small decrease in anisotropic singlet of peroxy radical. In this case, there were no obvious signals from the antioxidant radicals, probably due to its long-lasting action related to the decomposition of hydroperoxide groups and negligible concentration of them at steady state.

When both antioxidants were present in PE, the effects observed by EPR spectroscopy were found to be additive, and the main difference was the emergence of the $\mathrm{R}_{\mathrm{I} 1076} 1$ doublet.

\section{Polyethylene filled with ATH}

In the next stage of the research, the influence of ATH on PE radical processes was investigated. The amount of mineral in the composition was about $1 / 3$

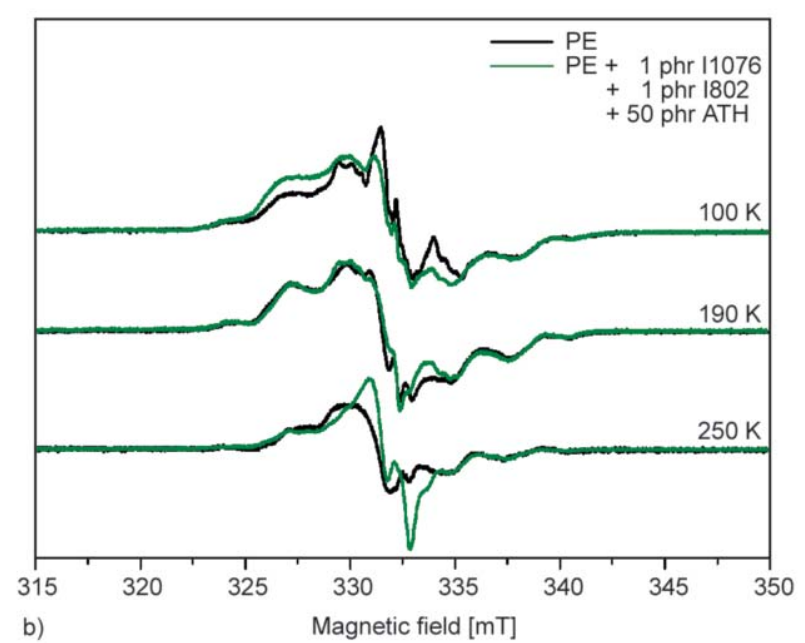

Figure 4. Sequences of EPR spectra of the materials gamma irradiated to a dose of $10 \mathrm{kGy}$ at $77 \mathrm{~K}$, upon annealing to the indicated temperatures. a) PE doped with $50 \mathrm{phr}$ of ATH; b) PE doped with 1 phr of I802 and 50 phr of ATH. 
of the total weight, thus a direct effect of radiation on both components, PE and ATH, was expected. At $100 \mathrm{~K}$, the presence of $\mathrm{O}^{-}$was confirmed (Figure 4a). However, the signal almost disappeared to $190 \mathrm{~K}$, and the only spectra attributed to ATH paramagnetic defects were found below this temperature. It seems that they did not affect the radical processes in PE. Their loss occurred at lower temperatures than in the case of native microcrystalline powder. Thus, the defects were more efficiently stabilized in microcrystals non-dispersed in the polymeric matrix. Probably during mixing the crystals were damaged and consequently their lattice was less effective in stabilizing paramagnetic centers causing their faster decay. Due to phase separation, there was no transfer of paramagnetic centers between PE and ATH.

Analogue processes occurred when additionally antioxidants were present in the system (Figure $4 b$ ). The ATH paramagnetic species also disappeared to $190 \mathrm{~K}$. Additionally, as in other systems doped with I1076, a $\mathrm{R}_{11076} 1$ doublet became visible.

\subsection{Relative concentration of radicals}

Figure 5 shows that the profiles of radical decay are similar for all studied polymeric materials. However,
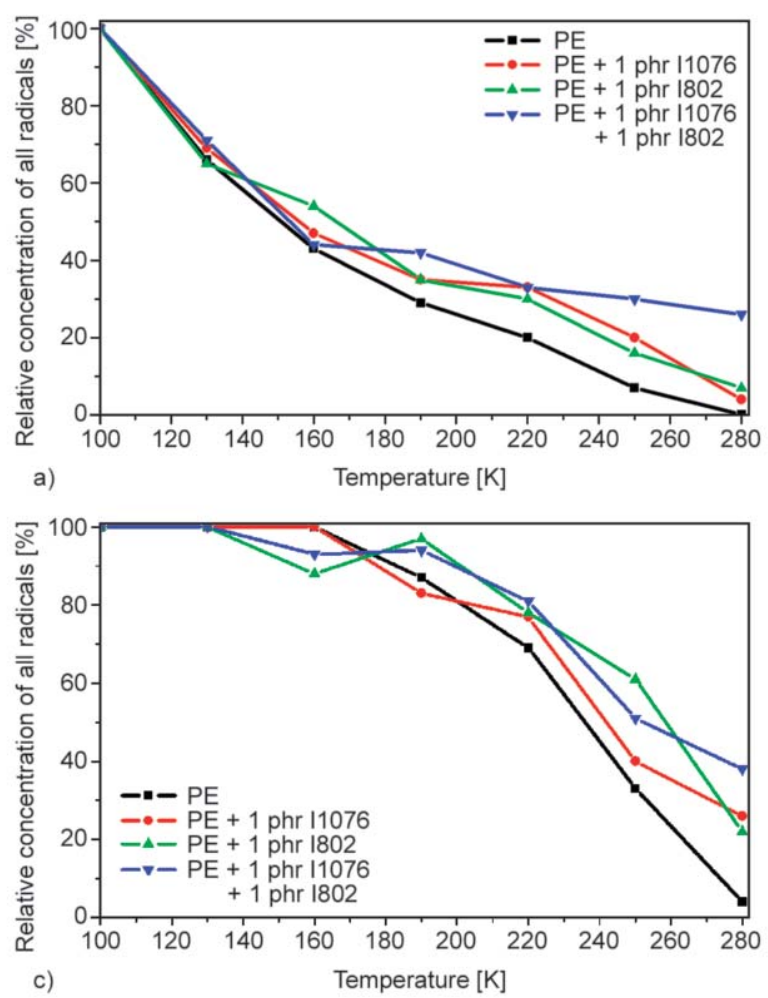

the gradual decrease in the relative concentration of all radicals is inconsistent with the decrease in the relative concentration of $\mathrm{R}_{\mathrm{PE}} 1$ alkyl radicals determined based on the reduction of the line's amplitude indicated in Figure 1a. The drop of $\mathrm{R}_{\mathrm{PE}} 1$ concentration is small to $190 \mathrm{~K}$, whereas above this temperature the radicals decay rapidly. This phenomenon is related to the conversion of paramagnetic centers to diamagnetic substances at temperatures below and above glass transition range, respectively. Alkyl radicals in the amorphous phase decay at lower temperatures than in crystallites due to more intensive conformational movements of macromolecules. As seen in Figure $5 \mathrm{a}$ and $5 \mathrm{~b}$, in the range of $100-190 \mathrm{~K}$ the relative decrease in concentration of all radicals is about $70 \%$. On the other hand, only $20 \%$ of $\mathrm{R}_{\mathrm{PE}} 1$ decays to $190 \mathrm{~K}$ (Figure $5 \mathrm{c}$ and $5 \mathrm{~d}$ ) which indicates that other PE radicals disappear at low temperatures, namely peroxy and allylic radicals. Under the conditions of measurement, in the first stages of processes, the oxygen present in PE was exhausted during oxidation of carbon centered radicals localized in the amorphous phase, therefore the contribution of peroxy radical decreases with increasing temperatures due to the lack of available $\mathrm{O}_{2}$ molecules and reactions with
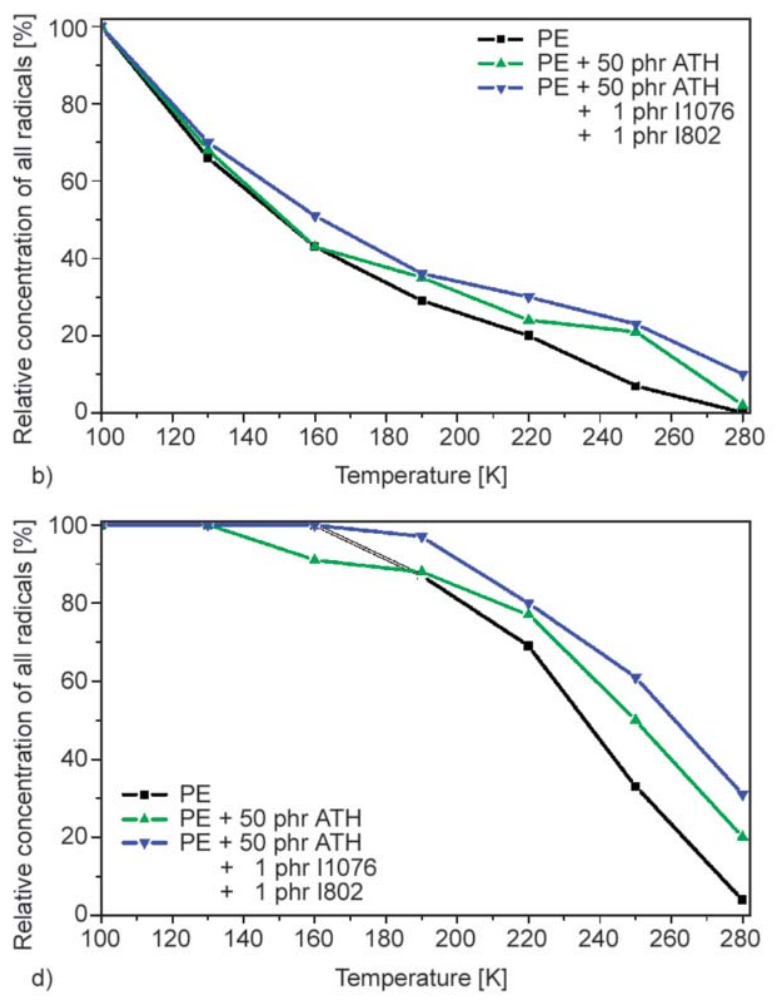

Figure 5. a) and b) decay of all radicals in PE materials in the presence of antioxidants or/and ATH as a function of annealing temperature. c) and d) decay of alkyl radicals in PE materials in the presence of antioxidants or/and ATH as a function of annealing temperature. 


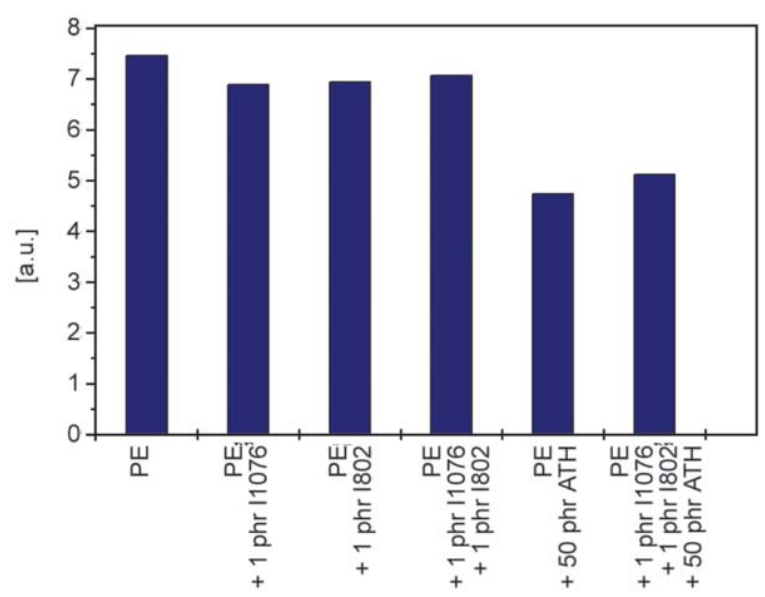

Figure 6. Comparison of radical content per gram of sample expressed as the double integral of the spectra recorded at $100 \mathrm{~K}$ normalized to the weight of the sample.

antioxidant. Additionally, as was confirmed in the past, allylic radicals were unstable and disappeared relatively fast [26].

Analyzing spectra presented in Figure 4a it was found that paramagnetic defects in ATH decayed at lower temperatures in PE matrix than in microcystalline powder. The question arises whether the effect results from the transfer of active centres to polymeric macromolecules or due to facilitated conversion to diamagnetic products. To explain this issue, the amout of paramagnetic centers (measured by double integration of spectra) per 1 gram of sample was determined at $100 \mathrm{~K}$ (Figure 6).

The concentration of radicals in the composites containing ATH is about 25\% lower than in ATH-free polyethylene. Thus, the observed effect was mainly due to the reduction of paramagnetic defects in ATH microcrystals because in the case of spins transfer between the dispersed phase and polymer matrix their total concentration in the sample should remain constant.

\section{Conclusions}

Research on radical processes in polymeric materials used in difficult environment is of increasing importance because their degradation inevitable reduces lifetime of the products made of plastics. These issues are crucial when radiation-induced aging of wires and cables in NPP is considered. EPR spectroscopy is the only technique used to follow directly radiation induced processes and to monitor the impact of additives applied to increase the functionality of insulating materials. Studies on the effect of components commonly used in cable industry on radiation chemistry of silane cross-linked PE showed that:

- Tested antioxidants (Irganox 1076 and 802) react with radicals generated in PE above the glass transition temperature. The phenolic antioxidant is ultimately a hydrogen donor although initially, in a transient structure, the proton is shared with the polymeric acceptor as evidenced by the doublet present in all EPR spectra for materials doped with I1076. At higher temperatures, the processes lead to the production of phenoxy radical stabilized by resonance [34] which shows the EPR signal in the form triplet of triplets.

- Irradiation of PE filled with ATH, the most commonly used flame retardant, initiates in the matrix the same radicals as in the ATH-free polymer and the radical processes occur in parallel and regardless of the presence of the dispersed phase. Paramagnetic defects in ATH crystalline powder are more stable than in microparticles dispersed in the PE matrix. Thus, the filler has neither positive nor negative impact on the processes initiated by radiation in polymer and on its degradation.

- PE radicals decay even under cryogenic conditions. Alkyl radicals detected by EPR spectroscopy are relatively stable because (i) the most labile $\mathrm{R}_{\mathrm{PE}} 1$ radicals participate in cross-linking, (ii) their conversion to peroxy radicals is limited by restricted oxygen availability under the condition of experiment, (iii) part of them can be considered as residual radicals trapped in the PE crystalline phase [22].

Currently, intermediate products and final compositions are subjected to long-term thermal and radiation aging to investigate macroscopic consequences of the observed radical processes.

\section{Acknowledgements}

The authors thank Nexans, France, (Jean-François Larché and Hakim Janah) for provided raw materials and compounds necessary to carry out these tests.

The TeaM Cables project has received funding from the Euratom research and training programme 2014-2018 under grant agreement No 755183 (European Tools and Methodologies for an efficient ageing management of nuclear power plant Cables). Scientific work partly financed from Polish financial resources for science in the years 2017-2022 allocated for the implementation of the international co-financed project. 


\section{References}

[1] IAEA-TECDOC-1188: VOL. 1, Assessment and management of ageing of major nuclear power plant components important to safety: In-containment instrumentation and control cables (2000).

[2] IAEA-TECDOC-1188: VOL. 2, Assessment and management of ageing of major nuclear power plant components important to safety: In-containment instrumentation and control cables (2000).

[3] IAEA Nuclear Energy Series: No. NP-T-3.6 Assessing and managing cable ageing in nuclear power plants (2012).

[4] Bartoníček B., Hnát V., Plaček V.: Assessment of the insulation degradation of cables used in nuclear power plants. Nuclear Instruments and Methods in Physics Research Section B: Beam Interactions with Materials and Atoms, 151, 423-426 (1999).

https://doi.org/10.1016/S0168-583X(99)00149-4

[5] Makuuchi K., Chen S.: Radiation processing of polymer materials and its industrial applications. Wiley, Hoboken (2012).

[6] Lyons B. J.: The effect of radiation on the physical and chemical properties of polyethylene containing an antioxidant and/or other additives. Radiation Physics and Chemistry, 42, 197-205 (1993).

https://doi.org/10.1016/0969-806X(93)90234-L

[7] Seguchi T., Tamura K., Shimada A., Sugimoto M., Kudoh H.: Mechanism of antioxidant interaction on polymer oxidation by thermal and radiation ageing. Radiation Physics and Chemistry, 81, 1747-1751 (2012). https://doi.org/10.1016/j.radphyschem.2012.06.011

[8] Boguski J., Przybytniak G., Mirkowski K.: Model studies on phenolic antioxidant role in radiation- and thermally-induced accelerated degradation of electrical cable insulation. Nukleonika, 57, 485-489 (2012).

[9] Chodák I.: Properties of crosslinked polyolefin-based materials. Progress in Polymer Science, 20, 1165-1199 (1995).

https://doi.org/10.1016/0079-6700(95)98859-N

[10] Torikai A., Geetha R., Nagaya S., Fueki K.: Radiationinduced degradation of polyethylene: Polymer structure and stability. Journal of Polymer Science Part A: Polymer Chemistry, 28, 3639-3646 (1990).

https://doi.org/10.1002/pola.1990.080281310

[11] Mandelkern L.: The relation between structure and properties of crystalline polymers. Polymer Journal, 17, 337-350 (1985).

https://doi.org/10.1295/polymj.17.337

[12] Popli R., Mandelkern L.: Influence of structural and morphological factors on the mechanical properties of the polyethylenes. Journal of Polymer Science Part B: Polymer Physics, 25, 441-483 (1987).

https://doi.org/10.1002/polb.1987.090250301
[13] Hassanpour S., Khoylou F.: Synergistic effect of combination of Irganox 1010 and zinc stearate on thermal stabilization of electron beam irradiated HDPE/EVA both in hot water and oven. Radiation Physics and Chemistry, 76, 1671-1675 (2007).

https://doi.org/10.1016/j.radphyschem.2007.02.090

[14] Pospíšil J.: Mechanistic action of phenolic antioxidants in polymers - A review. Polymer Degradation and Stability, 20, 181-202 (1988).

https://doi.org/10.1016/0141-3910(88)90069-9

[15] Pospíšil J.: Chemical and photochemical behaviour of phenolic antioxidants in polymer stabilization: A state of the art report, Part II. Polymer Degradation and Stability, 39, 103-115 (1993).

https://doi.org/10.1016/0141-3910(93)90130-B

[16] Jaworska E., Kałuska I., Strzelczak-Burlińska G., Michalik J.: Irradiation of polyethylene in the presence of antioxidants. Radiation Physics and Chemistry, 37, 285-290 (1991).

https://doi.org/10.1016/1359-0197(91)90143-P

[17] Gal O. S., Marković V. M., Novaković L. R., Stannett V. T.: The effects of the nature of the antioxidant on the radiation crosslinking of polyethylene. Radiation Physics and Chemistry, 26, 325-330 (1985).

https://doi.org/10.1016/0146-5724(85)90072-X

[18] Celina M., Gillen K. T., Wise J., Clough R. L.: Anomalous aging phenomena in a crosslinked polyolefin cable insulation. Radiation Physics and Chemistry, 48, 613-626 (1996). https://doi.org/10.1016/0969-806X(96)00083-7

[19] Menczel J. D., Judovits L., Prime R. B., Bair H. E., Reading M., Swier S.: Differential scanning calorimetry (DSC). in 'Thermal analysis of polymers: Fundamentals and applications' (eds.: Menczel J .D., Prime R. B) Wiley, Hoboken, 7-239 (2009).

https://doi.org/10.1002/9780470423837.ch2

[20] Buttafava A., Tavares A., Arimondi M., Zaopo A., Nesti S., Dondi D., Mariani M., Faucitano A.: Dose rate effects on the radiation induced oxidation of polyethylene. Nuclear Instruments and Methods in Physics Research Section B: Beam Interactions with Materials and Atoms, 265, 221-226 (2007).

https://doi.org/10.1016/j.nimb.2007.08.091

[21] Brunella V., Bracco P., Carpentieri I., Paganini M. C., Zanetti M., Costa L.: Lifetime of alkyl macroradicals in irradiated ultra-high molecular weight polyethylene. Polymer Degradation and Stability, 92, 1498-1503 (2007).

https://doi.org/10.1016/j.polymdegradstab.2007.05.005

[22] Kornacka E. M., Przybytniak G., Święszkowski W.: The influence of crystallinity on radiation stability of UHMWPE. Radiation Physics and Chemistry, 84, 151156 (2013). https://doi.org/10.1016/j.radphyschem.2012.06.027 
[23] Seguchi T., Tamura N.: Mechanism of decay of alkyl radicals in irradiated polyethylene on exposure to air as studied by electron spin resonance. Journal of Physical Chemistry, 77, 40-44 (1973).

https://doi.org/10.1021/j100620a008

[24] Jahan M. S., McKinny K. S.: Radiation-sterilization and subsequent oxidation of medical grade polyethylene: An ESR study. Nuclear Instruments and Methods in Physics Research Section B: Beam Interactions with Materials and Atoms, 151, 207-212 (1999).

https://doi.org/10.1016/S0168-583X(99)00083-X

[25] Singh A.: Irradiation of polyethylene: Some aspects of crosslinking and oxidative degradation. Radiation Physics and Chemistry, 56, 375-380 (1999). https://doi.org/10.1016/S0969-806X(99)00328-X

[26] Jahan M. S., Durant J.: Investigation of the oxygen-induced radicals in ultra-high molecular weight polyethylene. Nuclear Instruments and Methods in Physics Research Section B: Beam Interactions with Materials and Atoms, 236, 166-171 (2005).

https://doi.org/10.1016/j.nimb.2005.04.014

[27] Jahan M. S., King M. C., Haggard W. O., Sevo K. L., Parr J. E.: A study of long-lived free radicals in gammairradiated medical grade polyethylene. Radiation Physics and Chemistry, 62, 141-144 (2001). https://doi.org/10.1016/S0969-806X(01)00431-5

[28] Geetha R., Torikai A., Yoshida S., Nagaya S., Shirakawa H., Fueki K.: Radiation-induced degradation of polyethylene: Effect of processing and density on the chemical changes and mechanical properties. Polymer Degradation and Stability, 23, 91-98 (1989). https://doi.org/10.1016/0141-3910(89)90071-2

[29] Gallo S., Panzeca S., Longo A., Altieri S., Bentivoglio A., Dondi D., Marconi R. P., Protti N., Zeffiro A., Marrale M.: Testing and linearity calibration of films of phenol compounds exposed to thermal neutron field for EPR dosimetry. Applied Radiation and Isotopes, 106, 129-133 (2015). https://doi.org/10.1016/j.apradiso.2015.07.043

[30] Smith C. L., Ankers E., Best S. P., Gagliardi F., Katahira K., Tsunei Y., Tominaga T., Geso M.: Investigation of IRGANOX ${ }^{\circledR} 1076$ as a dosimeter for clinical X-ray, electron and proton beams and its EPR angular response. Radiation Physics and Chemistry, 141, 284-291 (2017). https://doi.org/10.1016/j.radphyschem.2017.08.002

[31] Marrale M., Gallo S., Longo A., Panzeca S., Parlato A., Buttafava A., Dondi D., Zeffiro A.: Study of the response of phenol compounds exposed to thermal neutrons beams for electron paramagnetic resonance dosimetry. Radiation Measurements, 75, 15-20 (2015). https://doi.org/10.1016/j.radmeas.2015.02.019
[32] Fehir R. J., McCusker J. K.: Differential polarization of spin and charge density in substituted phenoxy radicals. Journal of Physical Chemistry A, 113, 9249-9260 (2009). https://doi.org/10.1021/jp905314h

[33] Gadosy T. A., Shukla D., Johnston L. J.: Generation, characterization, and deprotonation of phenol radical cations. Journal of Physical Chemistry A, 103, 88348839 (1999).

https://doi.org/10.1021/jp992216x

[34] Lucarini M., Mugnaini V., Pedulli G. F., Guerra M.: Hydrogen-bonding effects on the properties of phenoxyl radicals. An EPR, kinetic, and computational study. Journal of the American Chemical Society, 125, 8318-8329 (2003). https://doi.org/10.1021/ja034963k

[35] Nizameev I. R., Pudovkin M. S., Kadirov M. K.: EPR, structural characteristics and intramolecular movements of some phenoxyl radicals in toluene. Magnetic resonance in solids. Electronic Journal, 12, 22-25 (2010).

[36] Witkowski A., Hollingbery L., Hull T. R.: Fire retardancy of mineral fillers in EVA copolymers. in 'Fire and polymers VI: New advances in flame retardant chemistry and science' (eds.: Morgan A. B., Wilkie C. A., Nelson G. L.) American Chemical Society, Washington, Vol 1118, 97-111 (2012). https://doi.org/10.1021/bk-2012-1118.ch007

[37] Sener A. A., Demirhan E.: The investigation of using magnesium hydroxide as a flame retardant in the cable insulation material by cross-linked polyethylene. Materials and Design, 29, 1376-1379 (2008). https://doi.org/10.1016/j.matdes.2007.05.008

[38] Basfar A. A.: Flammability of radiation cross-linked low density polyethylene as an insulating material for wire and cable. Radiation Physics and Chemistry, 63, 505-508 (2002).

https://doi.org/10.1016/S0969-806X(01)00545-X

[39] Kuruc J.: Paramagnetic centers by X-ray-irradiation of aluminum hydroxide. Journal of Radioanalytical and Nuclear Chemistry, 154, 61-72 (1991). https://doi.org/10.1007/BF02163064

[40] Gaur U., Wunderlich B.: The glass transition temperature of polyethylene. Macromolecules, 13, 445-446 (1980). https://doi.org/10.1021/ma60074a045 